\title{
Tratamento no modelo hospitalocêntrico: percepções de familiares e portadores de transtorno mental
}

\author{
Treatment on hospital-centered model: perceptions of relatives and individuals \\ affected by mental disturbance
}

\author{
Tratamiento en el modelo hospitalocéntrico: percepciones de familiares y portadores \\ de trastorno mental
}

\author{
Letícia de Oliveira Borba'; Andréa Noeremberg Guimarães ${ }^{\text {II }}$; Verônica de Azevedo Mazza ${ }^{\text {III }}$; Mariluci Alves Maftum ${ }^{I V}$
}

\begin{abstract}
RESUMO: Pesquisa com o método da história oral temática, desenvolvida no ano de 2009, em Curitiba, com oito participantes pertencentes a três famílias que tinham um integrante com transtorno mental. Objetivou-se descrever a percepção de familiares e de portadores de transtorno mental sobre a assistência em saúde mental sustentada no modelo hospitalocêntrico. Os dados foram obtidos por meio de entrevista semiestruturada e analisados de acordo com a análise temática. Os sujeitos atribuíram ao modelo hospitalocêntrico as sucessivas internações em instituições com características asilares, o emprego de espaços restritivos, como as celas fortes no tratamento da pessoa com transtorno mental. Mencionaram o uso da força, da sedação, da eletroconvulsoterapia, da contenção física no leito e do enfaixamento como recursos utilizados sem critérios e de forma indiscriminada. Conclui-se que as narrativas contribuem para o entendimento das mudanças atuais na forma de assistir e tratar da pessoa com transtorno mental. Palavras-Chave: Assistência em saúde mental; transtornos mentais; família; tratamento.
\end{abstract}

\begin{abstract}
Thematic oral history-based research conducted in Curitiba, PR, Brazil, in 2009, with eight subjects in three families with a member affected by mental disturbance. The study aimed at describing the perception of both those affected by mental disturbance and of their relatives on hospital-centered assistance for mental health. Data were obtained through semi-structured interviews and treated on the basis of thematic analysis. Subjects charged the hospital-centered model with the successive internments in shelter-like institutions, and with the restrictive spaces such as strong cells used in the treatment of those affected by mental disturbance. They reported the use of the force, sedation, electro-convulse-therapy, physical contention in bed, and bandaging as some of the resources used lacking criteria. In conclusion, narratives help understand current changes in the assistance of those with mental disturbance.

Keywords: Mental health assistance; mental disorders; family; treatment.
\end{abstract}

RESUMEN: Investigación con el método de la historia oral temática, desarrollada en el año 2009 en Curitiba, con ocho partícipes pertenecientes a tres familias que tenían un integrante con trastorno mental. Se persiguió describir la percepción de familiares y de portadores de trastorno mental sobre la asistencia en salud mental basada en el modelo hospitalocéntrico. Se obtuvieron los datos mediante entrevista semiestructurada y se analizaron según el análisis temático. Los sujetos atribuyeron al modelo hospitalocéntrico los sucesivos internamientos en instituciones con características asilares, el empleo de espacios restrictivos, como las celdas cerradas en el caso de tratamiento de persona con trastorno mental. Mencionaron el empleo de la fuerza, sedación, terapia electroconvulsiva, contención física en el lecho y vendajes como recursos utilizados sin criterios y de forma indiscriminada. Se concluye que las narrativas contribuyen a entender los cambios actuales en la manera de asistir y tratar a la persona con trastorno mental.

Palabras Clave: Asistencia en salud mental; trastornos mentales; familia; tratamiento.

\section{INTRODUÇÃO}

Em meados do século XVIII surgem os manicômios para responder às exigências da modernidade como instituição específica para isolar mendigos, prostitutas, vagabundos, e loucos da sociedade. Isso ocorreu em conformidade aos objetivos da revolução industrial, da ascensão da classe burguesa e da incompatibilidade entre a razão e a loucura difundida pelo pensamento racionalista moderno ${ }^{1}$.

IEnfermeira. Doutoranda em Enfermagem pelo Programa de Pós-Graduação em Enfermagem da Universidade Federal do Paraná. Membro do Núcleo de Estudos, Pesquisa e Extensão em Cuidado Humano de Enfermagem. Curitiba, Paraná, Brasil. E-mail: leticia_ufpr@yahoo.com.br

IIEnfermeira. Doutoranda em Enfermagem pelo Programa de Pós-Graduação em Enfermagem da Universidade Federal do Rio Grande do Sul. Professora Assistente do Departamento de Enfermagem da Universidade do Estado de Santa Catarina. Chapecó, Santa Catarina, Brasil.E-mail: andrea.guimaraes@udesc.br IIIEnfermeira. Doutora em Enfermagem. Docente do Departamento de Enfermagem e Coordenadora do Programa de Pós-Graduação em Enfermagem da Universidade Federal do Paraná. Coordenadora do Grupo de Estudos Família, Saúde e Desenvolvimento. Curitiba, Paraná, Brasil. E-mail: mazzas@ufpr.br

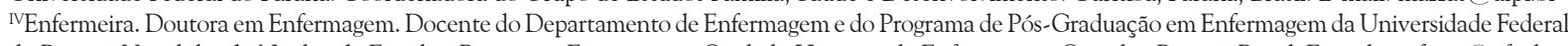
do Paraná. Vice-líder do Núcleo de Estudos, Pesquisa e Extensão em Cuidado Humano de Enfermagem. Curitiba, Paraná, Brasil. E-mail: maftum@ufpr.br 
No Brasil, no século XIX foi fundado no Rio de Janeiro o Hospício Dom Pedro II, inaugurado em 1852, um grande manicômio que manteve a tradição asilar de abrigar desviantes de todos os tipos, submetidos a diversas intervenções e arbitrariedades. Assim, o processo de institucionalização da loucura foi regido pelo discurso público da legitimidade e necessidade de exclusão das pessoas que perturbavam a ordem em locais específicos².

Entre as intervenções propostas estavam a normatização do comportamento, o controle do tempo, a rigidez de regras, o isolamento social e consequente perda da identidade e referência das pessoas segregadas. Essas práticas visavam reprogramar a existência dos sujeitos atendendo as exigências da ordem e da disciplina ${ }^{3,4}$.

Diante da realidade de superlotação, maustratos, terapêuticas centrada na força e punição, se iniciou um repensar das práticas na área da saúde mental, que conquistou espaço no Brasil a partir da década de 1980. Destarte, a prática e o saber nessa área do conhecimento vêm sendo transformados com mudanças no modo de conceber e tratar da pessoa com transtorno mental e na criação de novos dispositivos de tratamento de base comunitáriaa ${ }^{1,5,6}$.

Assim, investigar a assistência que foi oferecida às pessoas com transtorno mental antes da proposição e implantação do novo modelo assistencial se faz pertinente a fim de conhecimento e reflexão para que não se incorra no erro de mudar a estrutura, romper os muros, mas não o pensamento e as ações arcaicas. Além de preservar a história por meio do registro escrito dos fatos presentes na memória dos sujeitos que vivenciaram o tratamento no modelo manicomial.

Neste trabalho teve-se por objetivo descrever a percepção de familiares e de portadores de transtorno mental sobre a assistência em saúde mental sustentada no modelo hospitalocêntrico.

\section{REVISÃO DE LITERATURA}

Após a criação do Hospício Dom Pedro II no Rio de Janeiro em 1852, diversas regiões do país deram início a construção de grandes manicômios com o objetivo de controlar e moldar os comportamentos por meio da vigilância, do controle, da disciplina, da punição e da violência institucional, o que pressupunha tratar indivíduos insanos e irrecuperáveis ${ }^{5,7,8}$.

No Brasil República os manicômios continuaram a ser considerados locais apropriados para a reprogramação das formas de existir, e a dinâmica e o funcionamento permaneciam pautadas no restabelecimento da ordem. Essa conduta se reflete nos dias atuais quando nos deparamos com um contingente considerável de portadores de transtorno mental cronificados, alguns ainda residentes em hospitais psiquiátricos, sem identidade e sem vínculo familiar ${ }^{7,8}$.
A assistência dispensada aos portadores de transtorno mental no Brasil se assemelhava com a que era oferecida nos países da Europa, calcada na institucionalização. Relatórios dos presidentes dos estados de São Paulo, Rio Grande do Sul, Pernambuco e Pará durante toda a segunda metade do século XIX evidenciavam as precárias condições sanitárias e de espaço físico das instituições psiquiátricas, visto que os asilos espalhados pelo Brasil logo se tornaram superlotados e alvos de constantes denúncias de maus tratos aos internos ${ }^{1,2}$.

Após tentativas frustradas de recuperar a função terapêutica da instituição psiquiátrica, a realidade que se apresentava era a de um modelo assistencial não resolutivo. Os internos eram concebidos como agentes passivos, privados das necessidades humanas básicas, e cerceados nos seus direitos mais legítimos. Evidenciava-se uma verdadeira indústria da loucura ${ }^{5}$.

\section{Metodologia}

Pesquisa de História Oral Temática, realizada em 2009, com famílias que tinham um integrante com transtorno mental e residiam em Curitiba/PR e região metropolitana. Neste trabalho, considerou-se por família, a pessoa com transtorno mental e as pessoas que ela referiu como sua família.

Utilizou-se o referencial metodológico da História Oral na condução da pesquisa tanto para a entrevista como para estabelecer a comunidade de destino, a colônia e a rede?

A comunidade de destino é determinada considerando que o que marca a união das pessoas são dramas comuns, vivenciados com intensidade e consequências que de certo modo impõem mudanças na dinâmica da vida do grupo 9 . A comunidade de destino foi representada pelas famílias que vivenciaram o tratamento de um integrante com transtorno mental em face do modelo hospitalocêntrico.

A colônia é a primeira divisão da comunidade de destino, ela facilita o entendimento do todo e torna viável a realização do estudo? ${ }^{9}$. A colônia foi representada por famílias que vivenciaram o tratamento de um integrante com transtorno mental em face do modelo hospitalocêntrico em Curitiba e região metropolitana.

Rede é a subdivisão da colônia. Ela deve ser plural, porque nas diferenças internas dos grupos se expõe formas diversificadas de entendimento do fenômeno9. A rede foi constituída de famílias que vivenciaram a trajetória de tratamento da pessoa com transtorno mental anterior a 1980 até 1994 residentes em Curitiba e região metropolitana.

Os critérios de inclusão foram: famílias com pelo menos uma pessoa com transtorno mental que adoeceu em data anterior a 1980, década cujos vários acontecimentos marcam o início da reforma psiquiátrica no país, até 1994, aproximadamente, quando 
efetivamente se estabelece uma rede de assistência na área da saúde mental, orientada pelos princípios do modelo psicossocial em Curitiba/PR. Familiares que acompanharam a trajetória de tratamento da pessoa com transtorno mental, ser referido pelo portador de transtorno mental como família e ser maior de 18 anos.

Para estabelecer a rede de informantes, foi realizado contato com os responsáveis por duas associações de familiares e pessoas com transtorno mental, os quais indicaram os colaboradores. Os participantes indicados foram convidados e aceitaram participar da pesquisa, sendo três famílias, num total de oito colaboradores. As famílias foram denominadas F1, F2, F3, as pessoas com transtorno mental identificadas com nomes fictícios e os familiares, por relação de parentesco, conforme Figura 1.

O projeto foi aprovado pelo Comitê de Ética em Pesquisa do Setor de Ciências da Saúde da Universidade Federal do Paraná, sob o registro CAAE 3168.0.000.091-08. Foram salvaguardados os aspectos éticos de acordo com a Resolução no 196/96, do Conselho Nacional de Saúde.

Os dados foram obtidos mediante entrevista semiestruturada orientada por um roteiro composto de dados de identificação e duas questões abertas: Relate como você percebeu o tratamento recebido por seu familiar na saúde mental antes de 1994, dirigida aos familiares, e Relate como você percebeu o tratamento que recebeu na saúde mental antes de 1994, dirigida à pessoa com transtorno mental.

As entrevistas foram realizadas de acordo com a disponibilidade de cada colaborador e nos locais indicados por eles - associações e nos seus domicílios. Antes de iniciar as entrevistas, cada colaborador foi indagado se desejava narrar sua história em conjunto ou separadamente dos outros membros da família. Alguns preferiram ser entrevistados sozinhos e outros optaram por ser em conjunto. Foram realizadas cinco entrevistas gravadas em fita cassete no período de abril a junho de 2009 com a média de duração de uma hora.

Cada entrevista passou pelo processo de transcrição, textualização e transcriação conforme estabelece o referencial metodológico da história oral. A transcrição envolveu a conversão do oral para o escrito. Na textualização, realizou-se um refinamento do material para identificar o tom vital da entrevista. $\mathrm{Na}$ etapa de transcriação, recriou-se o texto seguindo um raciocínio lógico, que foi validado com cada colaborador a fim de não alterar o sentido de suas narrativas ${ }^{9}$.

As narrativas após a transcriação foram analisadas de acordo com a análise temática de Minayo ${ }^{10}$. As três categorias temáticas que emergiram foram: Sucessivas internações; Terapêuticas utilizadas pela instituição psiquiátrica; e $\mathrm{O}$ (des)cuidado com a pessoa internada em instituição hospitalocêntrica.

\section{Resultados e Discussão}

Na sequência são apresentadas as categorias temáticas exemplificadas com a fala de alguns dos colaboradores que fizeram parte deste estudo.

\section{Sucessivas internações}

Os colaboradores mencionaram as sucessivas internações em hospitais psiquiátricos, conhecida como o fenômeno da porta giratória e a não adesão ao tratamento farmacológico, conforme narrativas a seguir:

Ele não aceitava o tratamento, no hospital tomava a medicação ficava bem, voltava para casa, não tomava o remédio, caía de novo, tinha que internar novamente.. (F2Mãe)

Eu vivia [...] em hospital psiquiátrico, ficava em média seis meses internado. Eu era internado, ficava bem, voltava para casa, ficava ruim, era internado novamente. (F3Gustavo)

O internamento foi muito difícil para mim, ir para o hospital psiquiátrico com todos aqueles pacientes juntos, ficar longe da família. Quando eu recebia alta, voltava para casa, mas parava de tomar o remédio, tinha que internar novamente. (F2Paulo)

O fenômeno da porta giratória na área da saúde mental evidencia o fracasso do modelo de saúde predominantemente biomédico, sustentado na relação objeto-cura, esse modelo considera apenas os aspectos biológicos e não a complexidade das relações, da

\begin{tabular}{|lccclc|}
\hline Famílias & Integrantes & Idade & $\begin{array}{c}\text { Idade da 1 } \\
\text { crise/ Ano }\end{array}$ & $\begin{array}{c}\text { Estado } \\
\text { Civil }\end{array}$ & $\begin{array}{c}\text { Código dos } \\
\text { Colaboradores }\end{array}$ \\
\hline Família 1 & Mãe & 61 anos & & Casada & F1Mãe \\
& Pai & 72 anos & & Casada & F1Pai \\
& Irmã & 38 anos & & Casada & F1Irmã \\
Eduarda & 40 anos & 19 anos/ 1985 & Solteira & F1Eduarda \\
Família 2 & Mãe & 67 anos & & Viúva & F2Mãe \\
& Paulo & 38 anos & 23 anos/ 1994 & Solteiro & F2Paulo \\
Família 3 & Mãe & 66 anos & & Viúva & F3Mãe \\
& Gustavo & 47 anos & 17 anos/1982 & Solteiro & F3Gustavo \\
\hline
\end{tabular}

FIGURA 1: Caracterização dos Colaboradores. Curitiba, 2009 
subjetividade, do ambiente e do social sobre a saúde das pessoas. Assim, a produção de saúde nos serviços fechados é comprometida e a produção de cronicidade é preponderante. Estabelece-se uma relação de dependência entre o sujeito e o serviço de saúde que fragiliza a autonomia e a capacidade de reinserção social do paciente após o período que este ficou institucionalizado $^{11,12}$.

As situações que contribuem para a necessidade de recorrer ao internamento em instituição psiquiátrica versam sobre a não adesão ao tratamento medicamentoso, falta de acompanhamento após a alta hospitalar, de informação e orientação disponibilizada à família, a exclusão social pela estigmatização da loucura e à dificuldade em garantir a continuidade do tratamento na rede de serviços extra-hospitalares que deem conta do atendimento e intervenção nos momentos de crise $\mathrm{e}^{12-14}$.

Uma forma de romper o ciclo das internações é implantar e ampliar os serviços de saúde comunitários nos quais o sujeito é tratado em seu meio social, incorporar ações que o auxiliem a desenvolver novas habilidades em busca de autonomia e aumento de seu poder de contratualidade $6,12,14$.

Atividades relacionadas ao lazer, cultura, artesanato, atividade física, articulação com a rede de suporte social como igrejas, escolas, centros de convivência e clubes devem fazer parte do tratamento em saúde mental. Essa rede de cuidados aliada à mudança no estilo de vida, à terapia farmacológica e ao acompanhamento em serviços substitutivos são imprescindíveis para o processo de ressocialização e resgate e construção de novos vínculos ${ }^{4}$.

Quanto à adesão ao tratamento medicamentoso, estudo realizado com 167 pessoas portadoras de transtorno mental evidenciou que $60 \%$ faziam uso irregular da medicação prescrita ${ }^{15}$. A não adesão implica em novas crises, no aumento do número de hospitalizações/ reinternações que são permeadas por perdas nas mais diversas esferas da vida do indivíduo ${ }^{16,17}$. Ressalta-se a importância do tratamento farmacológico não de forma isolada, mas associado a outros recursos disponíveis que permitam à pessoa se expressar e conquistar o maior nível de autonomia possível.

\section{Terapêuticas utilizadas pela instituição psiquiátrica}

Os colaboradores mencionaram a força física, a sedação, as celas fortes e a eletroconvulsoterapia como terapêuticas utilizadas pela instituição psiquiátrica. A cela forte foi descrita como uma pequena sala na qual a pessoa ficava isolada, sem supervisão de um profissional de saúde e ao ser liberada apresentava-se confusa e desorientada.

Trabalhei 10 anos em hospital psiquiátrico, o tratamento era à base de choque, da força. Cansei de ver maltratar as pessoas. Receitavam eletrochoque, aplicavam injeção que derrubava a pessoa. (F1Pai)
O cubículo era uma salinha, com uma porta com um furo para olhar para dentro e uma janela de ferro. Pegavam a pessoa pelo pescoço e pelos braços e jogavam lá dentro para se acalmar por 3, 4 horas. Lá tinha uma cama de pedra e um cobertor. A pessoa ficava sem comer e sem beber. Se fosse após o jantar, eles jogavam no cubículo e a pessoa amanhecia lá. Eu fui para o cubículo uma vez, me pegaram e me jogaram lá, no escuro acabei dormindo, quando saí eu estava meio sem noção. (F3Gustavo)

Recebi eletrochoque porque eu não sentia alegria, tristeza, eles colocavam um colchão, ali, um segurava as pernas para não tremer, outro os braços, colocavam uma borracha para eu morder e dois negócios na cabeça [os eletrodos] que vinham de um aparelho parecido com um rádio. Quando ligava o aparelho, eu sentia um soco e dormia. Aí fui melhorando. (F3Gustavo)

Ele estava cada vez pior, uns três meses ficou lá e não melhorava, deram o eletrochoque nele, ele melhorou. (F3Mãe)

Graças a Deus que ela nunca levou eletrochoque. (F1Mãe)

A instituição manicomial tinha por objetivo utilizar dispositivos que caminhassem na direção da correção do que sinalizava anormalidade. Predominavam as relações de tutela, disciplina e controle, pouco flexíveis quanto ao poder de escolha dos internos. À instituição asilar cabia a responsabilidade de eliminar os sintomas da desordem psíquica. Para tanto, utilizava-se um acervo de recursos que iam desde a internação, técnicas de hidroterapia, administração excessiva de psicofármacos, até aplicação de estímulos elétricos ou o uso de procedimentos cirúrgicos ${ }^{18}$.

O uso de cubículos foi proibido por meio da Portaria SNAS no 224, de 29 de janeiro de 1992, a qual estabeleceu a proibição da existência de espaços restritivos, e celas fortes com vistas à necessidade de humanizar a assistência e assegurar os direitos de cidadania das pessoas com transtorno mental internadas nas instituições psiquiátricas ${ }^{19}$.

A eletroconvulsoterapia foi inserida como forma de tratamento em saúde mental em 1937, e pela fácil aplicação do método, a novidade foi imediatamente adota pelos hospitais psiquiátricos, porém, era utilizada de forma indiscriminada, associada ao castigo físico e ao controle disciplinar ${ }^{18,20}$.

Hoje, esta prática é indicada como recurso terapêutico em situações nas quais o paciente não reage com melhora a nenhuma outra medida de intervenção, nos quadros de depressão profunda e em quadros catatônicos ${ }^{18-21}$. A prática da eletroconvulsoterapia deve ser considerada após avaliação criteriosa e com a mensuração dos potenciais benefícios e riscos, incluindo: risco da anestesia, condição física, eventos adversos anteriores, principalmente perda cognitiva. Ainda, deve ser administrada somente após a ob- 
tenção do consentimento informado dos pacientes que apresentem capacidade para tanto ou de seus responsáveis ${ }^{22}$.

Também foram expressos pelos colaboradores como terapêuticas utilizadas pelo modelo hospitalocêntrico a contenção física no leito com faixas de tecido de algodão e o enfaixamento.

Fui contido porque eu queria fugir. Passei uma noite contido, eles me injetaram tranquilizante e não tive mais problema, mas foi muito traumatizante para mim. (F2Paulo)

No [nome de um hospital psiquiátrico] ir de um local para outro, eles proibiam, quando eu era internado eu costumava gritar e não podia, se gritasse, se cantasse alto sempre me continham. Eu não queria ir dormir, me levavam e me continham. De dia eu não lembro o que eu fazia, mas me continham também. (F3Gustavo)

Passei pelo enfaixamento, e me sentia mal, quando estava fora do limite eles me amarravam com uma faixa úmida. O enfaixamento é feito com faixa úmida e depois com mais duas secas. Ficava duas horas enfaixada, às vezes, até três. (F1Eduarda)

Tinha o enfaixamento. Ficava como uma múmia, não me lembro se é um pano molhado primeiro, depois outro seco para a pessoa ficar calma, ficava três horas. (F3Gustavo)

Sobre a técnica da contenção física no leito com faixas de tecido de algodão, é possível inferir que esta prática foi realizada muitas vezes de maneira inadequada e sem avaliação de sua necessidade ao considerar que o uso inadequado e indiscriminado da técnica de contenção física configurava a primeira escolha na abordagem do portador de transtorno mental, em detrimento a uma prática que valorizasse a abordagem sustentada na comunicação terapêutica.

$\mathrm{Na}$ atual conjuntura de assistência em saúde mental, não é aceitável que a contenção física se constitua procedimento de rotina nos serviços de saúde. Preconiza-se que ela seja utilizada como último recurso, depois de esgotadas todas as possibilidades de abordagem ao paciente por comunicação terapêutica. Nas situações de emergência psiquiátrica, preconiza-se o uso da escuta ativa e respeitosa, o acolhimento do sofrimento, a comunicação terapêutica e, se necessária, a contenção física ${ }^{23}$.

Quando for imprescindível lançar mão da contenção física no leito, é importante esclarecer ao paciente no momento da realização do procedimento o motivo da conduta, permitir e possibilitar a ele externar os sentimentos referentes à situação que está vivenciando, para que de fato a técnica seja terapêutica ${ }^{23-25}$.

A prescrição da técnica de contenção física é legalmente uma atribuição médica, conforme consta na Resolução no 1.598/2000 do Conselho Federal de Medicina $^{26}$. O Conselho Federal de Enfermagem em 2012, por meio da Resolução n ${ }^{\circ} 427 / 2012$, normatizou os procedimentos de enfermagem no emprego da contenção mecânica e estabeleceu entre os cuidados, com o paciente durante o período da contenção, o monitoramento do seu estado de consciência, dos sinais vitais e das condições de circulação sanguínea. Ainda, ressalta que a contenção física deve ser empregada como último recurso, sendo vetado o seu emprego com caráter de punição, disciplina e coerção ${ }^{27}$.

A técnica de enfaixamento referida pelos colaboradores consistia em conter o paciente com várias camadas de faixas largas de tecido de algodão, necessitava de pelo menos oito pessoas para sua realização. As duas camadas internas eram embebidas em água morna e as duas voltas externas feitas com faixa seca ${ }^{13,25}$.

Enfaixava-se a pessoa a partir das extremidades dos membros inferiores, deixando os pés livres para o controle da circulação sanguínea. A faixa era enrolada em volta do corpo em sentido ascendente em espiral até os ombros, passando por cima dos braços, estes mantidos em posição anatômica. Tal procedimento era repetido quatro vezes ${ }^{4,25}$.

Essa modalidade de contenção física era indicada para pacientes muito agitados, agressivos, em que a abordagem pela comunicação, a realização de atividades recreativas e a medicação se mostrassem insuficientes naquele momento para sua proteção e de outros ${ }^{13,24,25}$.

\section{$\mathrm{O}$ (des)cuidado com a pessoa internada em instituição hospitalocêntrica}

Uma das colaboradoras referiu que as pessoas internadas em instituições com características asilares permaneciam sujas, descalças, e até nuas. Mencionou a superlotação dos hospitais psiquiátricos, a perda da identidade e do poder de escolha dos pacientes.

Nós chegávamos ao hospital ele estava sujo, descalço, sem roupa. Era muita gente, tinha grades nas janelas, era enorme de alto, eles lá agarrados pedindo comida, nós íamos chegando e eles pedindo. Era muita gente, todos misturados. A primeira vez que ele ficou internado, eu ia levar comida para ele, chegava lá, ele estava nu. (F3Mãe)

Na narrativa da colaboradora é expressa claramente a imagem da instituição manicomial, segregadora e superlotada. Isso já era evidenciado em relatórios sobre a situação dos hospícios no Brasil durante toda a metade do século XIX, nos quais era registrado que a quantidade de internos crescia de forma assustadora, as vagas não eram suficientes, os internos viviam em condições subumanas e não havia pessoal qualificado para o trabalho. Ao adentrar na instituição manicomial o que se via eram centenas de pessoas nuas, imundas e fétidas ${ }^{2}$.

Nesse contexto, se insere a discussão sobre maus-tratos nas instituições psiquiátricas, a fim de, não permitir o emprego de tais práticas nessas instituições pode-se contar com Programa Nacional de Avaliação 
do Sistema Hospitalar/Psiquiatria, que tem, entre seus objetivos, a busca da humanização das práticas de assistência à pessoa com transtorno mental, a fiscalização e o fechamento de instituições insalubres que ainda tenham como terapêutica a violência institucional ${ }^{28}$.

A partir da Portaria n ${ }^{\circ} 251$, de 31 de Janeiro de 2002, entende-se por hospital psiquiátrico, instituição na qual a maioria dos leitos se destina ao tratamento especializado da clientela psiquiátrica em regime de internação. Estes serviços devem oferecer, de acordo com a necessidade de cada paciente, atividades de avaliação médico-psicológica e social, psicoterapia breve, terapia ocupacional, atendimento grupal, além de oferecer e ter espaço físico disponível para a prática de esportes, jogos, salas com televisão, música e ambiente para os momentos de lazer ${ }^{19}$.

Cabe ressaltar, que em momento de ampliação e solidificação de uma rede de serviços em saúde mental não se nega a existência de situações que necessitem de internação, mas tem-se o entendimento de que o atendimento da crise pode ser realizado por CAPS III, que dispõem de leitos psiquiátricos e em hospitais gerais. Considerando as dificuldades de implantação e de capacidade de atendimento destes serviços, o hospital psiquiátrico passa a ser utilizados como dispositivo de saúde após esgotadas todas as demais possibilidades de intervenção por parte dos serviços extra-hospitalares.

\section{ConClusão}

A percepção dos colaboradores deste estudo em relação ao modelo hospitalocêntrico, foram apresentadas nas categorias temáticas: Sucessivas internações; Terapêuticas utilizadas pela instituição psiquiátrica; e, $\mathrm{O}$ (des)cuidado com a pessoa internada em instituição hospitalocêntrica. Por meio delas, os colaboradores evidenciaram fatos que traduzem o momento histórico que vivenciaram, caracterizado por terapêuticas empregadas por meio da força, forte disciplina, medidas corretivas, ambientes insalubres, superlotados, coerção e isolamento.

Também mencionaram o fenômeno das sucessivas internações em instituições asilares, o que mostra que sem ações interdisciplinares e complementares não é possível atender com resolutividade as demandas oriundas de uma doença de curso crônico como o transtorno mental.

As narrativas dos colaboradores contribuem para recuperar a memória da assistência oferecida às pessoas com transtorno mental pela instituição hospitalocêntrica no decorrer dos anos. Isso contribui para o entendimento das mudanças que acontecem no presente, evidenciando a importância da discussão que se tem atualmente, em oferecer serviços de base comunitária, resolutivos, que promovam a reinserção social e autonomia das pessoas com transtorno mental.

\section{REFERÊNCIAS}

1.Amarante P. Loucos pela vida: a trajetória da reforma psiquiátrica no Brasil. Rio de Janeiro: SDE/ENSP; 1995. 2.Oda AMGR, Dalgalarrondo P. História das primeiras instituições para alienados no Brasil. História, Ciências, Saúde - Manguinhos. 2005; 12: 983-1010.

3.Melman J. Família e doença mental. 2a ed. São Paulo: Escrituras; 2006.

4.Salles MM, Barros S. Reinternação em hospital psiquiátrico: a compreensão do processo saúde/doença na vivência do cotidiano. Rev esc enferm USP. 2007; 41: 73-81.

5.Fraga MNO, Souza AMA, Braga VAB. Reforma psiquiátrica brasileira: muito a refletir. Acta Paul Enferm. 2006; 19: 201-11.

6.Delgado PGG. Mental health reform in Brazil: changing hospital-centered paradigma to ensure access to care. Urban Suffering Studies Care [Internet]. Milão; 2013 [cited in 2015 Jan 02]. 8 [13 telas] Disposable in: file:///C:/Users/Pavillion/Downloads/pedro\%202013\%20Mental\%20 health\%20reform\%20in\%20Brazil\%20(1).pdf

7.Moreno V, Alencastre MB. A trajetória da família do portador de sofrimento psíquico. Rev esc enferm USP. 2003; 37: 43-50.

8.Amarante P. Saúde mental e atenção psicossocial. Rio de Janeiro: Fiocruz; 2007.

9.Meihy JCSB, Holanda F. História oral: como pensar como fazer. São Paulo: Contexto; 2007.

10.Minayo MCS. O desafio do conhecimento: pesquisa qualitativa em saúde. São Paulo: Hucitec; 2004.

11.Ramos DKR, Guimarães J, Enders BC. Análise contextual de reinternações frequentes de portador de transtorno mental. Interface - Comunic, Saude, Educ. 2011; 15: 519-27.

12.Martí JB. La vulnerabilidad relacional: análisis del fenômeno y pautas de intervención. Revista Hispana para el Análisis de Redes Sociales [Scielo-Scientific Electronic Library Online]. 2006 [citado en 15 dec 2014]. 11(4) Disponible en: http://revista-redes.rediris.es/pdf-vol11/ Vol11_4.pdf

13.Borba LO. Vivência familiar de tratamento da pessoa com transtorno mental em face da reforma psiquiátrica [dissertação]. Curitiba (PR): Universidade Federal do Paraná; 2010.

14.Pinheiro TLS, Cazola LHO, Sales CM, Andrade ARO. Fatores relacionados com reinternações de portadores de esquizofrenia. Cogitare enferm. 2010; 15: 302-7. 15.Cardoso L, Galera SAF. Doentes mentais e seu perfil de adesão ao tratamento psicofarmacológico. Rev esc enferm USP. 2009; 43: 161-7.

16.DiBonaventura M, Gabriel S, Dupclay L, Gupta S, Kim E. A patient perspective of the impact of medication side effects on adherence: results of a cross sectional nationwide survey of patients with schizophrenia. BMC Psychiatry. 2012; 12(20).

17.Sylvia LG, Hay A, Ostacher MJ, Miklowitz DJ, Nierenberg AA, Thase ME, et al. Association between therapeutic aliance, care satisfaction, and pharmacological adherence in bipolar disorder. J clin psychopharmacol. 2013; 33: 343-50. 
18.Silva MLB, Caldas MT. Revisitando a técnica de eletroconvulsoterapia no contexto da reforma psiquiátrica brasileira. Psicol cienc prof. 2008; 28: 344-61.

19.Ministério da Saúde (Br). Saúde mental no SUS: os centros de atenção psicossocial. Brasília (DF): Ministério da Saúde; 2004.

20.Ministério da Saúde (Br). Memória da loucura: apostila de monitoria. Brasília (DF): Ministério da Saúde; 2008. 21.Santos Júnior A, Oliveira MC, Andrade TS, Freitas RR, Banzato CEM, Azevedo RCS, et al. Twenty years of electroconvulsive therapy in a psychiatric unit at a university general hospital. Trends Psychiatry Psychother. 2013; 35: 229-33.

22.Salleh MA, Papakostas I, Zervas I, Christodoulou G. Eletroconvulsoterapia: critérios e recomendações da Associação Mundial de Psiquiatria. Rev psiquiatr clin. 2006; 33: 262-7.

23. Estelmhsts P, Brusamarello T, Borille D, Maftum MA. Emergências em saúde mental: prática da equipe de enfermagem durante o período de internação. Rev enferm UERJ. 2008; 16: 399-403.

24.Paes MR, Borba LO, Brusamarello T, Guimarães AN, Maftum MA. Contenção física em hospital psiquiátrico e a prática da enfermagem. Rev enferm UERJ. 2009; 17: 479-84.

25.Paes MR, Borba LO, Maftum MA. Contenção física de pessoas com transtorno mental: percepções da equipe de enfermagem. Cienc cuid saude. 2011; 10: 240-7.

26.Conselho Federal de Medicina. Resolução no 1.598 de 09 de agosto de 2000. Normatiza o atendimento médico a pacientes portadores de transtorno mental. [Internet]. Brasília (DF): CFM; 2000 [citado em 15 jun 2014]. Disponível em: http://www.portalmedico.org.br/resolucoes/ cfm/2000/1598_2000.htm

27. Conselho Fe-deral de Enfermagem. Resolução n ${ }^{\circ} 427$ de 07 de maio de 2012. Normatiza os procedimentos de enfermagem no emprego da contenção mecânica de pacientes. Brasília (DF): COFEn; 2012 [citado em 18 jun 2014]. Disponível em: http://novo.portalcofen.gov. br/resoluo-cofen-n-4272012_9146.html

28.Ministério da Saúde $(\mathrm{Br})$. Secretaria de Atenção à Saúde. Programa Nacional de Avaliação dos Serviços Hospitalares PNASH - Psiquiatria [Internet]. Brasília; 2003 [citado em 15 mar 2014]. Disponível em: http://dtr2001.saude.gov.br/sas/pnashpsi/PNASH\%20 PSIQ\%20-\%20Versao\%202003.pdf 